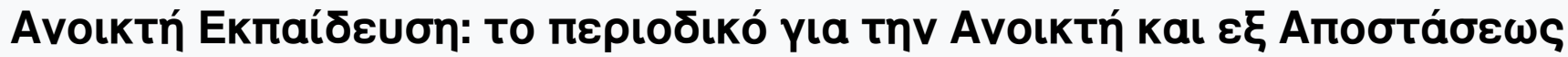

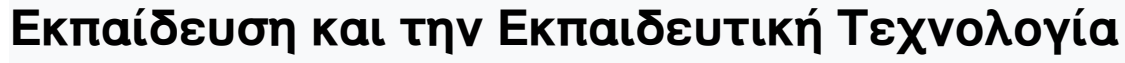

Tóн. 13, Ap. 2 (2017)

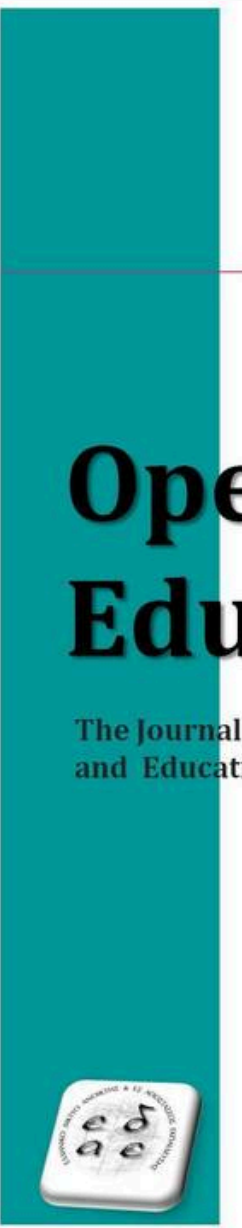




\title{
Instructional Design of the WaW e-courses
}

Maria Niari

PhD Candidate, Hellenic Open University niarimaria@gmail.com

Antonia-Maria (Tonia) Hartofylaka

Tutor, Hellenic Open University tonia.harto@gmail.com

\begin{abstract}
The current paper describes the process of the instructional design for the production of the WaW project e-learning courses by adapting the handbooks generated at intellectual outputs 3 and 4 (IO3, IO4: " $21^{\text {st }}$ Century Skills Handbook" and "Crowdfunding Handbook") to e-learning context. The aim was to produce and develop online e-learning materials suitable for the needs of the target group, as well as to develop innovative online learning content, e.g. video courses, animation, scenarios, etc, in order to foster learning and self-development skills. Users will be females representing all the different target groups while being either employed or unemployed, interested in creating the appropriate mindset and conditions. The ADDIE model (Analysis, Design, Development, Implementation, and Evaluation) was used for the production of the e-courses, not only because it is the generic process traditionally used by instructional designers and training developers, but mostly because it represents a dynamic, flexible guideline for building effective training and performance support tools. Instructional theories, such as behaviourism, constructivism, social learning and cognitivism, were taken into account as they also play an important role in the design of instructional materials.
\end{abstract}

\section{Keywords}

instructional design, ADDIE model, WaW project

\section{Introduction}

This paper describes the procedure that was followed for the production of the WaW project e-learning modules by adapting the handbooks generated at intellectual outputs 3 and 4 (IO3 and IO4: " $21^{\text {st }}$ Century Skills Handbook" and "Crowd-funding Handbook") to e-learning contexts. The aim was to produce and develop online elearning materials suitable to the needs of the target group, as well as to develop innovative online learning content, e.g. video courses, animation, scenarios, etc, in order to foster learning and self-development skills. Users will be females representing all the different target groups while being either employed or unemployed, interested in creating the appropriate mindset and conditions.

The ADDIE model was used for the production of the e-courses. The ADDIE model is the generic process traditionally used by instructional designers and training developers. The five phases - Analysis, Design, Development, Implementation, and Evaluation - represent a dynamic, flexible guideline for building effective training and performance support tools. 
Instructional theories also play an important role in the design of instructional materials. Theories such as behaviorism, constructivism, social learning and cognitivism help shape and define the outcome of instructional materials and were taken into account during the procedure of the instructional design and production of the WaW e-courses.

\section{Analysis phase}

In the analysis phase, instructional problem is clarified, the instructional goals and objectives are established and the learning environment and learner's existing knowledge and skills are identified (www.instructionaldesign.org, 2017).

The WaW project aims to "develop basic and transversal skills using innovative methods". This project promotes the development of basic and transversal skills, particularly entrepreneurial skills, though learner-centred and innovative methods that include e-learning and opportunities for virtual collaboration and networking. The target group is women who have the potential to make social and economic imprint, but who may otherwise lack the skills and opportunities to bring their dreams into a reality. Also, this project aims to empower immigrant, unemployed, older and/or disadvantaged women.

After having taken into account their needs, we decided to use interactive multimedia content in order for women to develop self-reflection and other self-development skills to acquire the needed skills for the 21st Century, based on cognitive objectives that focus on the learning of topics at different levels of comprehension.

\section{Instructional Design of the WaW e-courses}

Instructional Design is the systematic process by which instructional materials are designed, developed, and delivered. Also, the concept describes the process by which instruction is improved through the analysis of learning needs and systematic development of learning experiences. Instructional designers often use technology and multimedia as tools to enhance instruction.

According to Stemler (1997), the importance of instructional design is based on the fact that enables the instructors and tutors to:

- Identify a performance problem

- Determine the goals and objectives

- Define the learners and their needs

- Develop strategies to meet needs and goals

- Assess learning outcomes

- Evaluate if goals, objectives, and needs are met.

In the following units we describe the process for the adaption of the handbooks generated at IO3 and IO4 " $21^{\text {st }}$ Century Skills Handbook" and "Crowd-funding Handbook", to e-learning context.

\subsection{Interactive multimedia}

To meet the purposes of the intellectual output, we have used interactive multimedia, such as video courses, animation, interactive exercises, etc, as interactive multimedia is one of the most promising technologies of the time and has the potential to revolutionize the way we work, learn and communicate (Macromedia, 199; Staub \& Wetherbe, 1989). Interactive multimedia programs take the idea of learning and doing, not simply watching. With interactive multimedia programs the learning process becomes active, and it ensures that users are doing, not simply watching. Interactivity implies that the learning process is, in some degree, modified by the 
actions of the learners, thus changing the roles of both the learner and the teacher (Barker \& Tucker, 1990; Slawson, 1993, as ref. in Stemler, 1997).

\subsection{Gagne's nine events of learning}

In addition, we used the Gagne's (1985) nine events of learning, as a framework for the development of educational multimedia modules. The nine events include (a) gaining attention, (b) informing the learner of the lesson objectives(s) and activating motivation, (c) simulating recall of prior learning, (d) presenting the stimulus material, (e) providing learning guidance, (f) eliciting performance, (g) providing feedback, (h) assessing performance, and (i) enhancing retention and learning transfer.

\subsection{Screen design}

In the designing process we took into consideration the following basic principles, according to Stemler (1997):

- Well designed screens should allow for maximum learning from the materials while providing the learner with appropriate control of the learning process (Mlheim \& Lavix, 1992).

- Effective screen design causes learners to develop and maintain interest in lesson content, promotes the engagement of the learner with the material, and facilitates deep processing of important information (Faiola \& DeBloois, 1988; Hannafin \& Hooper, 1989; Milheim \& Lavix, 1992; Sponder \& Hilgerifeld, 1994).

- Screen designs should aid the user in the complex process of taking the information out of the program and integrating it into his or her own conceptual knowledge base (Jones, 1995), providing cognitive benefits in the user's ability to perceive, organize, and integrate information (Hannafin \& Hooper, 1989).

- Good screen designs are expected to fulfill a number of requirements: (a) focus learners' attention, (b) develop and maintain interest, (c) promote processing, (d) promote engagement between the learner and lesson content, (e) help learners find and organize information, and (f) facilitate lesson navigation (Grabinger, 1993; Hafinafin \& Hooper, 1989; Mukhedee \& Edmonds, 1993).

\subsection{Interaction}

As Herrington \& Oliver (2000:21) state "the instructional technology field abounds with argument about the importance of interactivity (e.g., Laurillard, 1996; Lockwood, 1992; Quinn, 1997; Schwier \& Misanchuk, 1993; 1994; Sims, 1995), in particular, how instructional technologies can be designed to include interactivity between the program and the learner".

Orr, Golas, and Yao (1994) give the following guidelines for increasing interactivity in multimedia programs:

$>$ Provide opportunities for interaction at least every three or four screens or, alternatively, about one per minute.

$>$ Chunk the content into small segments and build in questions (with feedback), periodic reviews, and summaries for each segment.

$>$ Ask as many questions as possible without interrupting the continuity of the instructional flow. Ask a question after, but not immediately following, the related content. Ask students a question that they can answer based on previously learned knowledge. Ask students to apply what they have learned rather than memorize and repeat answers. 
$>$ Use rhetorical questions during instruction to get students to think about the content, to stimulate student's curiosity.

$>$ Consider designs where the learner is not presented with information in a linear format, but rather discovers information through active exploration in the program.

\subsection{Navigation}

Regarding the learner's navigation in the e-learning context, we followed the Poncelet and Proctor's Guidelines for Interactivity (1993, as ref. in Stemler, 1997):

- Navigational Icons:

- Overview of instruction key for reviewing the introduction to the unit.

- Previous frame or next frame key for moving forward or backward in a lesson.

- Next lesson key for accessing the next lesson in a sequence.

- Menu key for exiting the lesson and return to the menu.

- Exit key for exiting the course.

- Analysis Icons:

- $\quad$ Summary key for seeing the summary or conclusions of the lesson.

- Review key for reviewing parts of the lesson

- $\quad$ Example key for seeing examples of an idea.

\subsection{Color}

Many authors (Schwier \& Misanchuk, 1995; Bailey \& Milheim, 1991; Faiola, 1990; Faiola \& DeBloois, 1988; McFarland, 1995; Milheim \& Lavix, 1992; Orr et al., 1994) have recommended specific guidelines for using color, including:

$\checkmark \quad$ using a maximum of three to six colors per screen;

$\checkmark \quad$ being consistent in color choices within a program;

$\checkmark \quad$ using it the brightest colors for the most important information;

$\checkmark \quad$ using a neutral gray or pastels as a background, since it recedes optically;

$\checkmark \quad$ using significant contrast between text and a background color to provide a higher degree of text readability;

$\checkmark \quad$ always using dark letters on a light background for text;

$\checkmark$ avoiding the use of complementary colors (e.g., blue/orange, red/green, violet/yellow);

$\checkmark \quad$ using commonly accepted colors for particular actions (e.g., red for stop or warning, yellow for pause or consider, green for go or proceed). Very hot colors (such as pink and magenta) should be avoided since they may appear to pulsate on the screen.

\subsection{Graphics}

According to Stemler (1997), "difficult topics sometimes become easier to understand when augmented by graphic displays (Gropper, 1983)". He also points out the following:

- Photos and scanned images can be used to illustrate almost any fact, concept, or procedure (Sponder \& Hilgenfeld, 1994).

- Information presented in text is often better recalled and retained when supplemented with pictures (Hooper \& Hannafin, 1988).

- Graphics are also used to represent icons and indicate to the user that a choice is available. E.g. left and right arrows indicate that users may go to the "next" and 
"previous" pages, etc.

\subsection{Animation}

Although animation can serve motivational and attention getting functions, no extra learning effects can be attributed to the use of animation (Hannafin \& Rieber, 1989, as ref.in Stemler, 1997). However, animation can be used both for the explanation of dynamic processes and for raising the impact of each presentation. As Rieber (1990, as ref. in Stemler, 1997) states "when the animation is congruent to the learning task, it can offer instructional benefits to the learners").

\subsection{Evaluation methodology}

During this phase, we also had to decide which is the most suitable method for assessment to be included in the WaW e-courses and platform, so as the achievement of the learning objectives can be determined. Taken into account the content of the ecourses and our target group's needs, we decided to develop two e-portfolios, one for each course.

A portfolio can be described as "a purposeful compilation and reflection of one's work, efforts and progress" (Bhattacharya \& Hartnett, 2007). There are different types of portfolio including assessment, employment, learning, and teaching portfolios, the format ultimately depending on the purpose for which it is developed.

According to McPherson (2010), a professional portfolio is a collection of artifacts that demonstrates a candidate's ongoing effort and developmental growth in one or more areas (Paulson, Paulson, \& Meyer, 1991). It can also be used as a marketing tool for job interviews to display evidence of knowledge and skills (Kilbane \& McNergney, 2001). The purpose of a portfolio system is to systematically organize evidence of meeting standards at three levels: curriculum of the program, faculty instruction and assessment, and candidates' reflection on learning. Barrett \& Carney (2005) also state that "a critical component of an educational portfolio is the learner's reflection on the individual pieces of work (often called "artifacts") as well as an overall reflection on the story that the portfolio tells".

E-portfolios, on the other hand, provide a web-based space where students can demonstrate their development of expertise in a wide range of skills and knowledge, whether in discipline knowledge or graduate capabilities. As suggested by Joyes et al (2009) e-portfolios can be used for a range of purposes in the learning process, for different audiences, at different times. In some fields, such as pre-service teacher education, e-portfolios are advocated as spaces to demonstrating evidence of reflections on learning during placements, practicum or skill development to prospective employers (Levin \& Camp, 2002; Berg and Lind, 2003 as ref. in McNeill \& Cram, 2011). Learning from both formal and informal contexts can be included, as decided by the learners, for selective sharing with others such as teachers, peers or prospective employers (Beetham, 2005).

Barrett (2000) states: "The process of developing electronic teaching portfolios can document evidence of teacher competencies and guide long-term professional development. The competencies may be locally defined, or linked to national teaching standards. Two primary assumptions in this process are: i) a portfolio is not a haphazard collection of artifacts (i.e., a scrapbook) but rather a reflective tool which demonstrates growth over time; and ii) as we move to more standards-based teacher performance assessment, we need new tools to record and organize evidence of successful teaching, for both practicing professionals and student teachers."

As there are many types and purposes for portfolios, for this project we decided to develop a type of portfolio that is a combination of a constructivist-type portfolio and 
positivist-type portfolio. A portfolio for demonstrating learning and reflection is a constructivist-type portfolio which shows growth and development over time, in contrast to a positivist-type portfolio which contains candidate's 'work' considered representative of knowledge and understanding for assessing learning outcomes, using data to report learning outcomes across users, contexts, and purposes (Paulson \& Paulson, 1994). As our aim is to empower learners to self-reflection and in the same time we need to evaluate the student's learning outcomes, we decided to develop a mixed type for the two portfolios.

\section{Development}

The development phase, according to the ADDIE model, is where the developers create and assemble the content assets that were created in the design phase. Subsequently, we delivered the courses to the consortium partners and we reviewed and revised the modules according to the feedback given.

\section{Implementation}

This phase has not yet been completed, as the WaW e-courses will be implemented in the following months.

\section{Evaluation}

Also, this phase has not yet been completed. There is provision for evaluation of the $\mathrm{WaW}$ e-courses in the following phases of the $\mathrm{WaW}$ project.

\section{References}

Bailey. H. J., and Milheim, W. D. (1991). A comprehensive model for designing interactive video based materials. Proceedings of the Ninth Conference on Interactive Instruction Delivery, 1991. Society for Applied Learning Technology Conference, Orlando, FL.

Barrett, H. (2000). Electronic Portfolios = Multimedia Development + Portfolio Development The Electronic Portfolio Development Process. Retrieved from http://electronicportfolios.com/portfolios/EPDevProcess.html\#ben (15/05/2017).

Bhattacharya, M. \& Hartnett, M. (2007). E-portfolio Assessment in Higher Education. 37th ASEE/IEEE Frontiers in Education Conference October 10 - 13, 2007, Milwaukee, WI.

Faiola, T. (1990). Principles and guidelines for a screen display interface. The Videodisc Monitor, 8(2), 27-29.

Faiola, T., \& DeBloois, M. (1988). Designing a visual factors based screen display interface: The new role of the graphic technologist. Educational Technology, 28(8), 12- 21.

Herrington, J., \& Oliver, R. (2000). An instructional design framework for authentic learning environments. Educational Technology Research and Development, 48(3), 23-48.

Kilbane, C., \& McNergeny, R. (2001). Focus on technology: Digital teaching portfolios build, display talent. $\quad$ Retrieved April $\quad 05, \quad 2005$ from http://www.aacte.org/Programs/Research/focus tech digital.htm

McFarland, R.D. (1995, February). Ten design points for the human interface to instructional multimedia. T.H.E. Journal, 67-69.

McNeill, M. \& Cram, A. (2011). Evaluating E-portfolios for university learning: Challenges and Opportunities. In G. Williams, P. Statham, N. Brown \& B. Cleland (Eds.), Changing Demands, Changing Directions. Proceedings ascilite Hobart 2011. (pp.862-873). http://www.ascilite.org.au/conferences/hobart11/procs/McNeill-full.pdf

McPherson, S. (2010). E-portfolio Systems for Performance Assessment and Program Evaluation. New Horizons for Learning, Fall 2010, retrieved from http://education.jhu.edu/PD/newhorizons/Journals/Fall2010/McPherson (10/05/2017).

Milheim, C.L., \& Lavix, C. (1992). Screen design for computer based training and interactive video: Practical suggestions and overall guidelines. Performance \& Instruction, 3(5), 13-21.

Orr, K. L, Golas, K. C., \& Yao, K. (1994) Storyboard development for interactive multimedia training. Journal of Interactive Instruction Development, 18-31. 
Paulson, F. \& Paulson, P. (1994). Assessing portfolios using the constructivist paradigm. Paper presented at AERA, New Orleans, ED376209.

Paulson, F., Paulson. P., \& Meyer, C. (1991). What makes a portfolio? Educational Leadership, 48(5), p.60-63.

Schwier, R. A. \& Misanchuk, E. R. (1995). The Art and Science of Color in Multimedia Screen Design, Part 1: Art, Opinion, and Tradition. Paper presented at the Annual Conference of the Association for Educational Communications and Technology (Anaheim, CA, February 8-12, 1995). Retrieved from http://files.eric.ed.gov/fulltext/ED381143.pdf (05/03/2017).

Stemler, L. (1997) Educational characteristics of multimedia: a literature review. Journal of Educational Multimedia and Hypermedia, 6(3-4), 339-359.

Note: The WaW project is funded by the Erasmus+ Programme of the European Union 